\title{
Anabolic Actions of Reduced and $S$-Carbamidomethylated Human Growth Hormone and Its Plasmin Digest in Man
}

\author{
Steven B. Heymsfield, Robert A. Bethel, Elmer C. Hall, John B. Mills, \\ Martha H. Moseley, Jack L. Kostyo, and Daniel Rudman \\ From the Departments of Medicine, Biometry, Biochemistry, and Physiology, Emory University \\ School of Medicine, and the Clinical Research Facility, Emory University Hospital, Atlanta, \\ Georgia 30322
}

A B S T R A C T Six children aged $12-15 \mathrm{yr}$, deficient in endogenous growth hormone, were each treated, after a 7 -day control period, for 7 days with $0.0168,0.052$, and $0.168 \mathrm{U} / \mathrm{kg}$ body $\mathrm{wt}^{3 / 4}$ human growth $(\mathrm{hGH})$ (doses $\mathrm{A}, \mathrm{B}$, and $\mathrm{C}$, respectively) in separate metabolic balance studies. Doses B and $\mathrm{C}$ caused a dose-related retention of $\mathrm{N}, \mathrm{P}, \mathrm{K}, \mathrm{Na}$, and $\mathrm{Cl}$ in ratios of $1 / 0.069$ / 4.5/7.5/5.6. These ratios indicate increments in masses of protoplasm/extracellular fluid $(\mathrm{ECF}) /$ bone in ratios of $1 / 2.0 /<0.001$.

Three of the children were also treated with doses $\mathrm{A}, \mathrm{B}$, and $\mathrm{C}$ of reduced and carbamidomethylated hGH (RCAM-hGH). Doses B and C caused 1.22.8 times as much retention of $\mathrm{N}, \mathrm{P}$, and $\mathrm{K}$, and $0.3-$ 0.5 times as much retention of $\mathrm{Na}$ and $\mathrm{Cl}$, as did the corresponding doses of $\mathrm{hGH}$. The plasmin digest of RCAM-hGH gave results generally similar to RCAMhGH. For RCAM-hGH and its plasmin digest, N, P, $\mathrm{K}, \mathrm{Na}$, and $\mathrm{Cl}$ were retained in ratios of about 1 / $0.14 / 5.4 / 2.2 / 2.1$, indicating increments of protoplasm/ $\mathrm{ECF} /$ bone of about 1/0.8/0.05.

These findings indicate that reduction and carbamidomethylation alter the anabolic actions of hGH in man in both quantitative and qualitative manner. RCAM-hGH is more potent in stimulating enlargement of protoplasm and bone, and less potent in stimulating expansion of ECF, than is the native hormone. The profile of anabolic actions of RCAM-hGH in man does not appear to be further altered by digestion with plasmin.

Received for publication 17 September 1976 and in revised form 7 February 1977.

\section{INTRODUCTION}

Injection of human growth hormone $(\mathrm{hGH})^{1}$ in growth hormone $(\mathrm{GH})$-deficient children causes retention of the lean body elements $\mathrm{N}, \mathrm{P}, \mathrm{K}, \mathrm{Na}$, and $\mathrm{Cl}$ with simultaneous gain in weight $(1-3)$. The retention of $\mathrm{N}$ and $\mathrm{K}$ reflects net formation of protoplasm; retention of $\mathrm{Na}$ and $\mathrm{Cl}$ manifests expansion of extracellular fluid (ECF); the retained $\mathrm{P}$ is deposited in both protoplasm and bone. These "anabolic" effects of the hormone can be quantitatively assayed by measuring the effects of standard doses of hGH on daily balances of each element by the metabolic balance study technique of Reifenstein et al. (4).

Certain changes can be made in the structure of hGH without destroying its biologic activities. The hormone can be digested by plasmin without reducing its potency in stimulating weight gain by the hypophysectomized rat (5), and without lessening anabolic potency in man (5). Furthermore, the disulfide bonds of hGH can be reduced without affecting its capacity to cause the hypophysectomized rat to gain weight, provided the sulfhydryl groups produced by reduction are protected with an uncharged blocking group (6). Such a preparation of reduced and $S$-carbamidomethylated hGH (RCAM-hGH) was shown to cause $\mathrm{N}$ retention in two GH-deficient subjects at the dose of $5 \mathrm{mg} /$ day $(7,8)$, but, without dose-response data and

${ }^{1}$ Abbreviations used in this paper: BW, body weight; ECF, extracellular fluid; $\mathrm{GH}$, growth hormone; hGH, human growth hormone; RCAM-hGH, reduced and $S$-carbamidomethylated human growth hormone; PD-RCAM-hGH, plasmin digest of reduced and $S$-carbamidomethylated human growth hormone. 


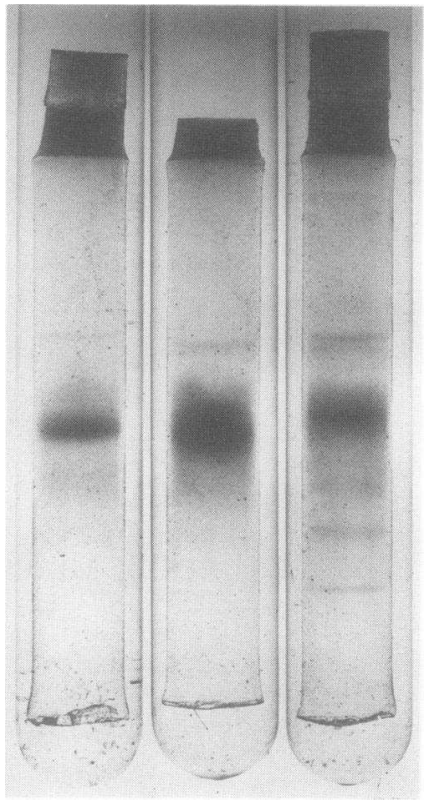

Figure 1 Acrylamide gel electropherograms at pH 9.0 of purified hGH (left), RCAM-hGH (center), and PD-RCAMhGH (right).

measurement of other elemental balances, a possible qualitative or quantitative difference in anabolic potency for man between hGH and RCAM-hGH cannot be excluded. RCAM-hGH, like hGH itself, can be cleaved by plasmin without changing its potency in the rat weight-gain assay (9). This preparation has not previously been assayed in man.

A change in the structure of a peptide hormone which possesses several biologic properties may not influence all properties in the same way $(10,11)$.
If a particular structural change should alter the biologic profile of $\mathrm{hGH}$, this could be of practical importance (e.g. a reduction in diabetogenic potency or an increase in anabolic potency). Furthermore, learning how specific chemical alteration of hGH affects each of its biologic properties will elucidate the structural bases for the several actions of the hormone. The purpose of the present study, accordingly, was to compare the anabolic actions of hGH, RCAM$\mathrm{hGH}$, and the plasmin digest of RCAM-hGH (PDRCAM-hGH) in human subjects.

\section{METHODS}

Growth hormone preparations. The starting material for the three $\mathrm{GH}$ preparations tested in the patients (purified hGH, RCAM-hGH, and PD-RCAM-hGH) was clinical grade hGH furnished by the National Pituitary Agency. The clinical grade material was purified by chromatography on DEAEcellulose according to Mills et al. (12). A portion of the purified hGH in turn was converted to RCAM-hGH and PDRCAM-hGH as previously described $(6,9)$. Acrylamide gel electropherograms $(7.5 \%$ gel, $\mathrm{pH} 9.0)$ (13) of the three preparations are shown in Fig. 1 . The potencies of $\mathrm{hGH}$, RCAM-hGH, and PD-RCAM-hGH were estimated by their capacity to cause hypophysectomized rats to gain weight (14) and were found to be $1.39 \pm 0.10,1.46 \pm 0.08$, and 1.60 $\pm 0.08 \mathrm{U} / \mathrm{mg}$ (average $\pm \mathrm{SE}$ for three assays). Each preparation was tested in man at doses $\mathrm{A}, \mathrm{B}$, and $\mathrm{C}$, which represent $0.0168,0.053$, and $0.168 \mathrm{U} / \mathrm{kg}$ body weight ${ }^{3 / 4}\left(\mathrm{BW}^{3 / 4}\right)$, respectively. These doses are equally spaced on a logarithmic scale.

Subjects. Six children, age $12-15 \mathrm{yr}$, who were totally deficient in endogenous growth hormone, were studied. Some patients were also deficient in thyroid-stimulating hormone (TSH), corticotropin (ACTH), luteinizing hormone, follicle-stimulating hormone, or antidiuretic hormone (ADH). Clinical data are summarized in Table I. Methods for the endocrine evaluation have been given in a previous report (3). Deficiencies of TSH, ACTH, or ADH had been corrected

TABLE I

Clinical Data of the Patients

\begin{tabular}{|c|c|c|c|c|c|c|c|c|c|}
\hline Case & Age & Sex & Ht & $\mathrm{wt}_{\mathrm{t}}$ & $\begin{array}{l}\text { Bone } \\
\text { age }\end{array}$ & Diagnosis & $\begin{array}{c}\text { Duration } \\
\text { since } \\
\text { diagnosis }\end{array}$ & $\begin{array}{l}\text { Pituitary hormone } \\
\text { deficiencies }\end{array}$ & $\begin{array}{l}\text { Hormone } \\
\text { replacement } \\
\text { treatment }\end{array}$ \\
\hline & $y r$ & & $\mathrm{~cm}$ & $\mathrm{~kg}$ & $y r$ & & $y r$ & & \\
\hline 1 & 14 & $\mathbf{F}$ & 120 & 22 & 10 & Idiopathic GH deficiency & 5 & GH & None \\
\hline 2 & 12 & $\mathbf{M}$ & 123 & 32 & 6 & Idiopathic GH deficiency & 5 & GH & None \\
\hline 3 & 15 & $\mathbf{M}$ & 147 & 56 & 11 & $\begin{array}{l}\text { Hypopituitarism secondary to } \\
\text { craniopharyngioma, excised }\end{array}$ & 8 & $\begin{array}{l}\text { GH, ACTH, TSH, } \\
\text { FSH, }{ }^{*} \text { LH, } \neq \text { ADH }\end{array}$ & $\begin{array}{l}\text { Cortisol, thy- } \\
\text { roxine, ADH }\end{array}$ \\
\hline 4 & 15 & $\mathbf{F}$ & 147 & 45 & 12 & $\begin{array}{l}\text { Hypopituitarism secondary to } \\
\text { craniopharyngioma, excised }\end{array}$ & 3 & $\begin{array}{l}\text { GH, ACTH, TSH, } \\
\text { FSH, }{ }^{*} \text { LH, } \neq \text { ADH }\end{array}$ & $\begin{array}{l}\text { Cortisol, thy- } \\
\text { roxine, ADH }\end{array}$ \\
\hline 5 & 12 & $\mathbf{M}$ & 118 & 31 & 12 & Idiopathic hypopituitarism & 6 & GH, ACTH, TSH & $\begin{array}{l}\text { Cortisol, thy- } \\
\text { roxine }\end{array}$ \\
\hline 6 & 14 & $\mathbf{M}$ & 147 & 58 & 10 & Idiopathic GH deficiency & 7 & GH & None \\
\hline
\end{tabular}

* Follicle-stimulating hormone.

\$ Luteinizing hormone. 
TABLE II

Order of Testing Doses and Hormone Preparations in Each Subject

\begin{tabular}{|c|c|c|c|c|c|c|}
\hline \multirow[b]{2}{*}{ Experiment } & \multicolumn{6}{|c|}{ Subject } \\
\hline & 1 & 2 & 3 & 4 & 5 & 6 \\
\hline 1 & $\mathrm{hGH}(\mathrm{A})^{*}$ & RCAM-hGH (B) & hGH (B) & PD-RCAM-hGH (A) & PD-RC.AM-hGH (C) & $\mathrm{hGH}(\mathrm{A})$ \\
\hline 2 & RCAM-hGH (A) & $\mathrm{hGH}(\mathrm{C})$ & $\mathrm{hGH}(\mathrm{A})$ & $\mathrm{hGH}(\mathrm{C})$ & $\mathrm{hGH}(\mathrm{B})$ & PD-RCAM-hGH (C) \\
\hline 3 & $\mathrm{hGH}(\mathrm{B})$ & RCAM-hGH (C) & RCAM-hGH (A) & PD-RCAIf-hGH (C) & PD-RCAM-hGH (A) & PD-RCA.I-hGH (B) \\
\hline 4 & RCAM-hGH (B) & $\mathrm{hGH}(\mathrm{A})$ & RCAM-hGH (B) & $\mathrm{hGH}(\mathrm{B})$ & $\mathrm{hGH}(\mathrm{A})$ & $\mathrm{hCH}(\mathrm{C})$ \\
\hline 5 & RCAM-hGH (C) & $\mathrm{hGH}(\mathrm{B})$ & RCAM-hGH (C) & PD-RCAM-hGH (B) & PD-RCAM-hGH (B) & PI-RCAM-hGH (A) \\
\hline 6 & PD-RCAM-hGH (C) & PD-RCAII-hGH (C) & PD-RCAM-hGH (C) & $\mathrm{hGH}(\mathrm{A})$ & $h G H(A)$ & $\mathrm{hGH}(\mathrm{B})$ \\
\hline 7 & $\mathrm{hGH}(\mathrm{C})$ & RCAM-hGH (A) & $\mathrm{hGH}(\mathrm{C})$ & & & \\
\hline
\end{tabular}

* hGH at dose $\mathrm{A}$.

by replacement treatment with thyroxine, cortisol, or vasopressin for $1 \mathrm{yr}$ or longer before the present experiments began. If the patient was under treatment with $\mathrm{hGH}$, such therapy was suspended for 3 mo before each experiment described here.

The experiments were done with the approval of Emory University Clinical Trials Committee and with the informed consent of the patients and their parents.

Experimental design. During the $2 \mathrm{yr}$ of the study, the six subjects were each admitted for six to seven 21-day periods in order to measure anabolic responses. Admissions were at 2-mo intervals or longer to avoid possible carryover effects. Three subjects (no. 1, 2, and 3 in Table I) received $h G H$ and RCAM-hGH at doses $A, B$, and $C$;

\section{TABLE III}

Average Increase in Daily Balance of $N, P, K, N a$, and $\mathrm{Cl}$ and in BW Achieved by Three Subjects Receiving hGH, RCAM-hGH, or PD-RCAM-hGH at Three Doses

\begin{tabular}{|c|c|c|c|c|c|c|}
\hline \multicolumn{2}{|l|}{ Column } & (1) & (2) & (.3) & (4) & (5) \\
\hline & \multirow[b]{2}{*}{ Dose } & \multicolumn{3}{|c|}{ Subjects 1-3 } & \multicolumn{2}{|c|}{ Subjects 4-6 } \\
\hline $\begin{array}{l}\text { Anabolic } \\
\text { response }\end{array}$ & & $\mathrm{hGH}$ & $\begin{array}{c}\text { RCAM- } \\
\text { hGH }\end{array}$ & $\begin{array}{c}\text { PD- } \\
\text { RCAM- } \\
\text { hCH }\end{array}$ & $\mathrm{hGH}$ & $\begin{array}{c}\text { PD- } \\
\text { RCAM- } \\
\text { hGH }\end{array}$ \\
\hline \multirow[t]{3}{*}{$\Delta \mathrm{N}$} & A & 0.23 & 0.27 & & 0.07 & 0.23 \\
\hline & B & 0.73 & 0.93 & & 0.27 & 0.97 \\
\hline & C & 1.37 & 1.63 & 1.60 & 0.80 & 1.57 \\
\hline \multirow[t]{3}{*}{$\Delta \mathrm{P}$} & A & 0.00 & 0.07 & & 0.00 & 0.00 \\
\hline & B & 0.04 & 0.11 & & -0.01 & 0.12 \\
\hline & C & 0.09 & 0.19 & 0.32 & 0.07 & 0.22 \\
\hline \multirow[t]{3}{*}{$\Delta \mathrm{K}$} & A & 1.43 & 4.10 & & -2.40 & -0.02 \\
\hline & B & 3.70 & 5.30 & & 2.33 & 5.77 \\
\hline & $\mathrm{C}$ & 5.87 & 5.70 & 7.27 & 3.57 & 7.77 \\
\hline \multirow[t]{3}{*}{$\Delta \mathrm{Na}$} & A & 4.50 & 0.43 & & -0.33 & 1.77 \\
\hline & B & 7.17 & 2.00 & & 4.07 & 2.33 \\
\hline & $\mathrm{C}$ & 9.57 & 2.63 & 3.43 & 7.17 & 3.23 \\
\hline \multirow[t]{3}{*}{$\Delta \mathrm{Cl}$} & A & 3.73 & 1.03 & & 2.07 & 0.27 \\
\hline & B & 4.57 & 2.40 & & 2.30 & 2.90 \\
\hline & C & 6.87 & 1.97 & 3.13 & 5.17 & 4.20 \\
\hline \multirow[t]{3}{*}{$\Delta \mathrm{BW}$} & A & 0.01 & 0.00 & & -0.01 & 0.00 \\
\hline & B & 0.05 & 0.02 & & 0.01 & 0.03 \\
\hline & C & 0.09 & 0.04 & 0.05 & 0.06 & 0.06 \\
\hline
\end{tabular}

another three subjects (no. 4, 5, and 6) received hGH and PD-RCAM-hGH at doses A, B, and C. The order of testing the various doses and hormone preparations in each subject was randomized (Table II). In addition, subjects 1, 2, and 3 each received a final treatment with dose $C$ of $P D-$ RCAM-hGH.

During the first 3 days of each admission, the patient adapted to the metabolic balance study diet. Adaptation was followed sequentially by a 7-day "control" period during which the patient received intramuscularly $2 \mathrm{ml} 0.9 \% \mathrm{NaCl}$ daily at 10 p.m., then a 7 -day "experimental" period of $\mathrm{GH}$ preparation intramuscularly at 10 p.m. in $2 \mathrm{ml} 0.9 \% \mathrm{NaCl}$.

The increments in daily balance of $\mathrm{N}, \mathrm{P}, \mathrm{K}, \mathrm{Na}$, and $\mathrm{Cl}$ during experimental as compared to control period, and the increase in $\mathrm{BW}$, were the indicators of anabolic response. These changes in balances or in $\mathrm{BW}$ were expressed per kilogram $\mathrm{BW}^{3 / 4} \times 10^{-1}$ per day in these units: $\Delta \mathrm{N}$ and $\Delta \mathrm{P}$, grams; $\Delta \mathrm{Na}, \Delta \mathrm{Cl}$, and $\Delta \mathrm{K}$, milliequivalents; $\Delta \mathrm{BW}$, kilograms. Experimental details for the balance studies have been given before (3).

Under conditions specified in Results, plasma immunoreactive $\mathrm{hGH}$ was measured by radioimmunoassay (15). In this assay, purified hGH, RCAM-hGH, and PD-RCAM-hGH gave parallel curves for [percentage of inhibition of binding of ${ }^{125} \mathrm{I}-\mathrm{hGH}$ ] vs. [concentration of unlabeled $\mathrm{hGH}$ preparation ]. RCAM-hGH and its plasmin digest, however, were only $60-70 \%$ as potent as purified hGH in displacing ${ }^{125} \mathrm{I}-\mathrm{hGH}$ from the antiserum.

\section{RESULTS}

Data of the 38 balance studies in six subjects. The data of all 38 balance studies are compiled in an appendix filed with the National Auxiliary Publication Service ${ }^{2}$ and are presented in summary form in Table III and Fig. 2. In Table III, each value represents the average change in daily balance of $\mathrm{N}, \mathrm{P}, \mathrm{K}, \mathrm{Na}$, and $\mathrm{Cl}$ and in $\mathrm{BW}$ achieved by three subjects between the experimental and control periods. Fig. 2 portrays the average responses of subjects 1,2 , and 3 or subjects 4,5 , and 6 to their specific preparation-dose combina-

${ }^{2}$ An Appendix has been deposited with the National Auxiliary Publications Service (NAPS) as NAPS document no. 03096. This information may be ordered from ASIS/NAPS, Microfiche Publications, P.O. 3515, Grand Central Station, New York 10017. Remit in advance $\$ 3.00$ for microfiche copy, or for photocopy, $\$ 5.00$ up to 20 pages plus $25 \notin$ for each additional page. Checks should be made payable to Microfiche Publications. 


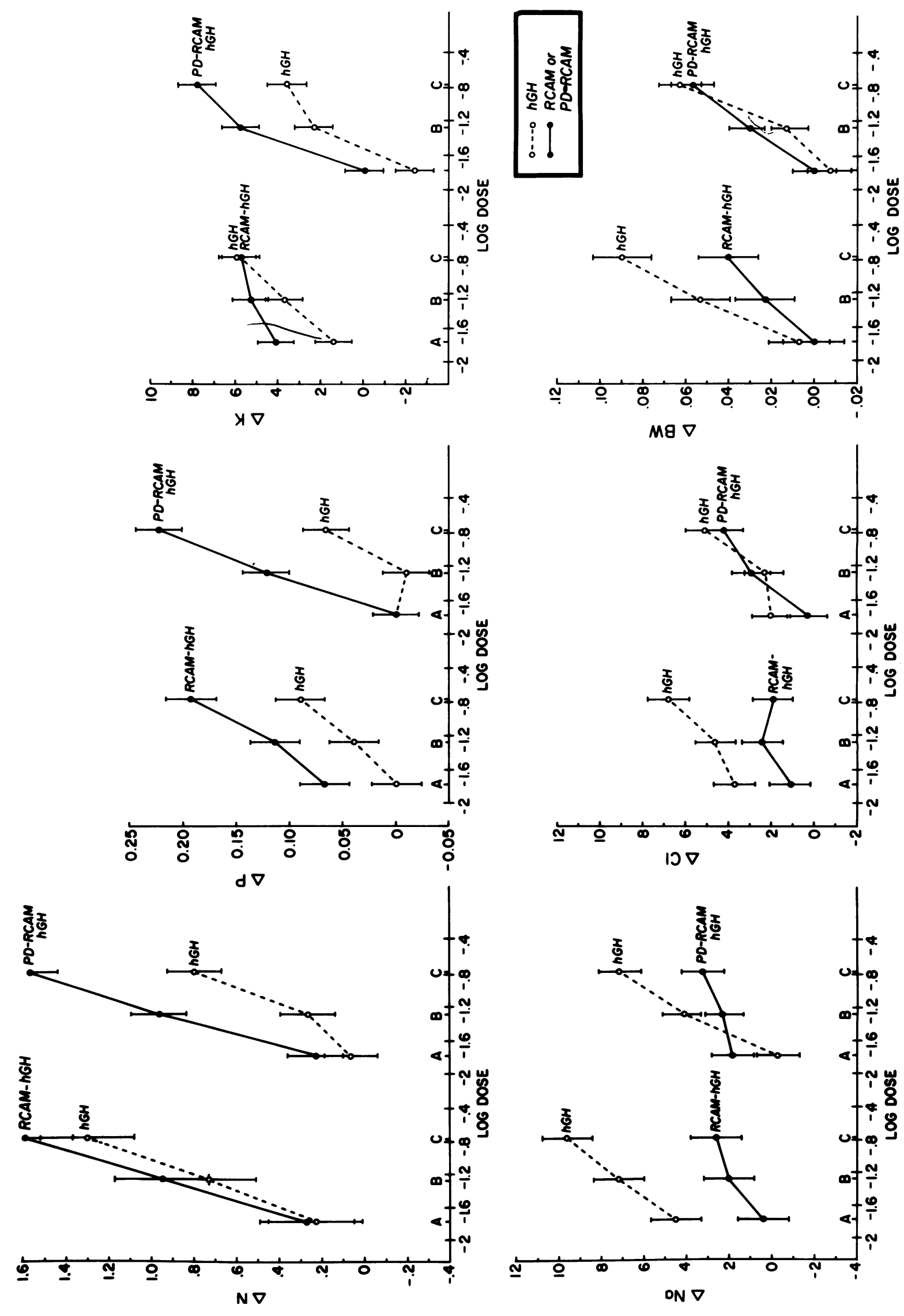


tions; i.e. each point plotted represents the mean incremental change of three subjects for a specific preparation and dose.

Several features of the experimental results are evident upon examination of Table III and Fig. 2: $(a)$ Subjects 1-3 differed substantially from subjects 4-6 in their anabolic responses to hGH at all three doses (cf. columns 1 and 4 in the table). On the average and individually, subjects $1-3$ produced larger incremental anabolic responses than subjects 4-6. (b) For $\mathrm{N}, \mathrm{P}$, and $\mathrm{K}, \mathrm{hGH}$ caused smaller average incremental responses than either RCAM-hGH (cf. columns 1 and 2) or PD-RCAM-hGH (cf. columns 4 and 5). (c) For $\mathrm{Na}, \mathrm{Cl}$, and $\mathrm{BW}$, hGH caused larger average incremental responses than either RCAM-hGH (cf. columns 1 and 2) or PD-RCAM-hGH (cf. columns 4 and 5). (d) In general, incremental responses were roughly linearly related to dose (on a logarithmic scale). Of course, in those instances where dose levels produced no (or negative) incremental changes, linearity should not be expected (e.g. graph of $\Delta \mathrm{P}$ in Fig. 2 , doses A and B of hGH for subjects 4-6). Linearity of the dose-response relationship, however, was visually supported in all subjects where the doses were all above a "threshold" level. (e) For each anabolic response, dose-response curves for the three preparations were roughly parallel. As in $(d)$, parallelism was visually supported in subjects where all doses were above a threshold level. $(f)$ Although individual subjects are not shown in Fig. 2, intersubject variation is indicated by the vertical bars located at each point. The length of each bar represents 1 SEM above and below the mean response of three subjects. The standard errors are based on a pooling of intersubject and "experimental error" variance components from the analysis of variance of each three-subject experiment.

Statistical analysis of the data. An analysis of variance model was developed to provide a basis for statistical inferences about the effects of preparations, doses, and subjects. Each three-subject experiment and anabolic response was analyzed separately; that is, for each of the six response variables $\mathrm{N}, \mathrm{P}$, $\mathrm{K}, \mathrm{Na}, \mathrm{Cl}$, and $\mathrm{BW}$, there were two three-subject experiments, one comparing hGH and RCAM (subjects 1,2 , and 3 ), and the other comparing $\mathrm{hGH}$ and PD-RCAM-hGH (subjects 4-6). Each of the 12 experiments had the layout shown in Table IV.

Inasmuch as each subject received both preparations and all three doses, an appropriate analysis of variance model is

$$
\mathrm{Y}_{i j k}=\mu+\mathrm{P}_{i}+\mathrm{D}_{j}+\mathrm{S}_{k}+I_{i j}+\mathrm{E}_{i j k} ;
$$

where $\mathrm{Y}_{i j k}$ is the anabolic response for the $i$ th prepara-
TABLE IV

Experimental Layout for Comparison of $h G H$ and RCAM-hGH or PD-RCAM-hGH at Three Doses in Three Subjects*

\begin{tabular}{cccc}
\hline Dose & Subject & $\begin{array}{c}\text { Preparation 1 } \\
\text { (hGH) }\end{array}$ & $\begin{array}{c}\text { Preparation 2 } \\
\text { (RCAM-hGH or } \\
\text { PD-RCAM-hGH) }\end{array}$ \\
\hline \multirow{2}{*}{$\mathrm{A}$} & 1 & $\mathrm{Y}_{111}$ & $\mathrm{Y}_{211}$ \\
& 2 & $\mathrm{Y}_{112}$ & $\mathrm{Y}_{212}$ \\
& 3 & $\mathrm{Y}_{113}$ & $\mathrm{Y}_{213}$ \\
B & 1 & $\mathrm{Y}_{121}$ & $\mathrm{Y}_{221}$ \\
& 2 & $\mathrm{Y}_{122}$ & $\mathrm{Y}_{222}$ \\
& 3 & $\mathrm{Y}_{123}$ & $\mathrm{Y}_{223}$ \\
$\mathrm{C}$ & 1 & $\mathrm{Y}_{131}$ & $\mathrm{Y}_{231}$ \\
& 2 & $\mathrm{Y}_{132}$ & $\mathrm{Y}_{232}$ \\
& 3 & $\mathrm{Y}_{133}$ & $\mathrm{Y}_{233}$ \\
\hline
\end{tabular}

* $\mathrm{Y}_{i j k}$ represents the anabolic response of the $k$ th subject at the $j$ th dose of the $i$ th preparation; e.g., $Y_{123}$ is the response of the third subject receiving dose $\mathrm{B}$ of $\mathrm{hGH}$.

tion, $j$ th dose, and $k$ th subject; $\mu$ is the overall mean response; $\mathrm{P}_{i}$ is the effect of the $i$ th preparation, $i=1,2 ; \mathrm{D}_{j}$ is the effect of the $j$ th dose, $j=1,2,3$; $S_{k}$ is the effect of the $k$ th subject, $k=1,2,3 ; I_{i j}$ is the interaction effect of preparations and doses; and $\mathrm{E}_{i j k}$ is the experimental error component comprised of a pooling of other possible interaction terms which, in these experiments, are assumed to be negligible or nonexistent. The nature of the experiments is such that an independent estimate of experimental error is not available. However, the model and assumptions appear to be valid based on a graphical examination of Fig. 2 and by statistical comparisons of the various interaction terms in the analysis of variance.

Table $\mathrm{V}$ summarizes the results of the 12 analyses of variance. Each line of the table indicates the statistical significance of the effects from the analysis of variance of each anabolic response. Differences between hGH and RCAM-hGH or PD-RCAM-hGH were significant $(P<0.05)$ for nine of the 12 experiments. All differences between hGH and RCAM-hGH were significant: averages for $\Delta \mathrm{N}, \Delta \mathrm{P}$, and $\Delta \mathrm{K}$ were greater with RCAM-hGH than with hGH, whereas averages for $\Delta \mathrm{Na}, \Delta \mathrm{Cl}$, and $\Delta \mathrm{BW}$ were greater with $\mathrm{hGH}$ than with RCAM-hGH. Averages for $\Delta \mathrm{N}, \Delta \mathrm{P}$, and $\Delta \mathrm{K}$ were greater with PD-RCAM-hGH than with $\mathrm{hGH}$; averages for $\Delta \mathrm{Na}, \Delta \mathrm{Cl}$, and $\Delta \mathrm{BW}$ were not significantly different for PD-RCAM-hGH vs. hGH. Statistical comparisons of RCAM-hGH and PD-RCAMhGH are not appropriate since they were employed in different three-subject experiments.

FIGURE 2 Summary of anabolic responses of subjects $1 \rightarrow 6$ to hGH, RCAM-hGH and PDRCAM-hGH. Each point represents average $\pm \mathrm{SE}(n=3)$. In each panel, the two curves on the left represent subjects $1-3$, and the two curves on the right represent subjects 4-6. 
TABLE V

Summary Results of the Analysis of Variance: Statistical Significance and Average Anabolic Responses

\begin{tabular}{|c|c|c|c|c|c|c|c|}
\hline \multirow[b]{2}{*}{$\begin{array}{l}\text { Anabolic } \\
\text { response }\end{array}$} & \multirow[b]{2}{*}{ Comparisons of preparations } & \multicolumn{4}{|c|}{ Effect ${ }^{*}$} & \multicolumn{2}{|c|}{ Average response } \\
\hline & & $\begin{array}{c}\text { Preparation } \\
\mathrm{P}_{1}\end{array}$ & $\begin{array}{l}\text { Dose } \\
D_{j}\end{array}$ & $\begin{array}{l}\text { Subject } \\
\mathrm{s}_{k}\end{array}$ & $\begin{array}{c}\text { Interaction } \\
\quad \mathrm{I}_{i j}\end{array}$ & $\begin{array}{c}\text { Preparation } 1 \\
\quad(\mathrm{~h}-\mathrm{GH})\end{array}$ & $\begin{array}{c}\text { Preparation } 2 \\
\text { (RCAM-hGH or } \\
\text { PD-RCAM-hGH) }\end{array}$ \\
\hline$\Delta \mathrm{N}$ & $\begin{array}{l}\text { hGH vs. RCAM-hGH } \\
\text { hGH vs. PD-RCAM-hGH }\end{array}$ & $\begin{array}{l}0.05 \\
0.001\end{array}$ & $\begin{array}{l}0.001 \\
0.001\end{array}$ & $\begin{array}{l}\text { NS } \\
\text { NS }\end{array}$ & $\begin{array}{l}\text { NS } \\
\text { NS }\end{array}$ & $\begin{array}{l}0.77 \\
0.378\end{array}$ & $\begin{array}{l}0.943 \\
0.922\end{array}$ \\
\hline$\Delta \mathrm{P}$ & $\begin{array}{l}\text { hGH vs. RCAM-hGH } \\
\text { hGH vs. PD-RCAM-hGH }\end{array}$ & $\begin{array}{l}0.001 \\
0.001+\end{array}$ & $\begin{array}{l}0.01 \\
0.001 \ddagger\end{array}$ & $\begin{array}{l}\text { NS } \\
\text { NS }\end{array}$ & $\begin{array}{l}\text { NS } \\
0.05\end{array}$ & $\begin{array}{l}0.043 \\
0.019 \ddagger\end{array}$ & $\begin{array}{l}0.124 \\
0.116\end{array}$ \\
\hline$\Delta \mathrm{K}$ & $\begin{array}{l}\text { hGH vs. RCAM-hGH } \\
\text { hGH vs. PD-RCAM-hGH }\end{array}$ & $\begin{array}{l}0.05 \\
0.001\end{array}$ & $\begin{array}{l}0.01 \\
0.001\end{array}$ & $\begin{array}{l}0.05 \\
\text { NS }\end{array}$ & $\begin{array}{l}\text { NS } \\
\text { NS }\end{array}$ & $\begin{array}{l}3.667 \\
1.167\end{array}$ & $\begin{array}{l}5.033 \\
4.533\end{array}$ \\
\hline$\Delta \mathrm{Na}$ & $\begin{array}{l}\text { hGH vs. RCAM-hGH } \\
\text { hGH vs. PD-RCAM-hGH }\end{array}$ & $\begin{array}{r}0.001 \\
\text { NS } \ddagger\end{array}$ & $\begin{array}{l}0.05 \\
0.01+\end{array}$ & $\begin{array}{l}\text { NS } \\
\text { NS }\end{array}$ & $\begin{array}{l}\text { NS } \\
0.05\end{array}$ & $\begin{array}{l}7.078 \\
3.633 \ddagger\end{array}$ & $\begin{array}{l}1.689 \\
2.444+\frac{t}{\ddagger}\end{array}$ \\
\hline$\Delta \mathrm{Cl}$ & $\begin{array}{l}\text { hGH vs. RCAM-hGH } \\
\text { hGH vs. PD-RCAM-hGH }\end{array}$ & $\begin{array}{r}0.01 \\
\text { NS }\end{array}$ & $\begin{array}{l}\text { NS } \\
0.05\end{array}$ & $\begin{array}{l}\text { NS } \\
\text { NS }\end{array}$ & $\begin{array}{l}\text { NS } \\
\text { NS }\end{array}$ & $\begin{array}{l}5.056 \\
3.178\end{array}$ & $\begin{array}{l}1.800 \\
2.456\end{array}$ \\
\hline$\Delta \mathrm{BW}$ & $\begin{array}{l}\text { hGH vs. RCAM-hGH } \\
\text { hGH vs. PD-RCAM-hGH }\end{array}$ & $\begin{array}{r}0.05 \\
\text { NS }\end{array}$ & $\begin{array}{l}0.01 \\
0.001\end{array}$ & $\begin{array}{l}\text { NS } \\
\text { NS }\end{array}$ & $\begin{array}{l}\text { NS } \\
\text { NS }\end{array}$ & $\begin{array}{l}0.050 \\
0.023\end{array}$ & $\begin{array}{l}0.021 \\
0.029\end{array}$ \\
\hline
\end{tabular}

* NS indicates that the effect is not significant, i.e., $P>0.05 ; 0.05,0.01$, and 0.001 indicate levels of statistical significance achieved.

$\$$ Subject to interaction of preparation and dose.

With one exception, dose effects were all significant $(0.001<P<0.05)$ as might be expected from the slopes of the lines in Fig. 2. Also with one exception, subject effects were not significant. This is somewhat surprising from a graphical and tabular perspective; however, as a consequence of the small size of the experiments (three subjects each) and the nature of the experiments error term in the analysis of variance, the tests for subject effect are not very sensitive.

In support of the parallelism of the dose-response lines noted in Fig. 2, in only two experiments $(\Delta P$ and $\Delta \mathrm{Na})$ was the interaction of preparations and doses significant $(P=0.05)$. For $\Delta \mathrm{P}$ (hGH vs. PD-RCAMhGH), examination of Fig. 2 and Table III indicates that doses $\mathrm{A}$ and $\mathrm{B}$ of $\mathrm{hGH}$ were below a threshold level, thereby introducing nonparallelism (implied by significant interaction) of the dose-response lines. In the other experiment (Fig. 2), the two dose-response lines cross between doses $A$ and $B$ reflecting the relative flatness of the PD-RCAM-hGH dose-response line in this experiment.

The last two columns of Table $\mathrm{V}$ show the anabolic responses of each preparation averaged over doses and subjects for each experiment. With the exception of the two experiments noted in the preceding paragraph, these columns may be used to suggest the relative activities of the two preparations (hGH vs. RCAMhGH or hGH vs. PD-RCAM-hGH). However, the design of the three-subject experiments does not permit the computation of the "usual" bioassay estimates of potencies and their associated confidence intervals.
Thus, the statistical analysis confirms that RCAMhGH and PD-RCAM-hGH are more potent than hGH in causing retention of $\mathrm{N}, \mathrm{P}$, and $\mathrm{K}$, and that RCAM$\mathrm{hGH}$ is less potent than hGH in causing retention of $\mathrm{Na}$ and $\mathrm{Cl}$. The data are not sufficiently extensive to quantify these differences in potency, or to compare the potencies of RCAM-hGH and PD-RCAM-hGH.

Plasma levels of immunoreactive hGH. In each subject, 6-8 mo after completion of the balance studies described above, plasma immunoreactive hGH was measured before and at $1-2 \mathrm{~h}$ intervals up to $12 \mathrm{~h}$ after a single intramuscular injection of dose $\mathrm{C}$ purified hGH, RCAM-hGH, or PD-RCAM-hGH. The hormone was injected at 8 a.m.; patients ate ad lib. at 9 a.m., 1 p.m., and 4 p.m. The three experiments were separated by 5-8 days in each subject. Fig. 3 shows that plasma immunoreactive hGH was $<1$ $\mathrm{ng} / \mathrm{ml}$ before the injection. The plasma $\mathrm{hGH}$ level vs. time curve was similar for the three hormone preparations in that the plasma level reached a maximum at $3 \mathrm{~h}$ and declined to baseline at $8 \mathrm{~h}$. Peak value averaged 13.8, 9.1, and $8.7 \mathrm{ng} / \mathrm{ml}$ for purified $\mathrm{hGH}$, RCAM-hGH, and PD-RCAM-hGH, respectively. This difference is consistent with the fact that the latter two preparations are only $60-70 \%$ as potent as the former in displacing ${ }^{125} \mathrm{I}-\mathrm{hGH}$ from the antiserum used in the radioimmunoassay.

\section{DISCUSSION}

The present results on effects of hGH on elemental balances of GH-deficient children are similar to those 
previously reported (3): threshold dose for $\mathrm{N}$ retention is generally dose $\mathrm{B}$; at dose $\mathrm{C}$, magnitude of $\Delta \mathrm{N}$ is in range +0.8 to $+1.7 \mathrm{~g} / \mathrm{kg} \mathrm{BW}^{3 / 4} \times 10^{-1} /$ day; and profile of the anabolic effects at doses $B$ and $C$, expressed as ratio $\Delta \mathrm{N} / \Delta \mathrm{P} / \Delta \mathrm{K} / \Delta \mathrm{Na} / \Delta \mathrm{Cl}(\Delta \mathrm{N}$ being assigned a value of 1 ) averages $1 / 0.069 / 4.5 / 7.5 / 5.6$. In terms of the Reifenstein equations (4), ${ }^{3}$ these ratios indicate that $\mathrm{hGH}$ during the lst wk of replacement treatment in hGH-deficient children causes increase in masses of protoplasm, ECF, and bone in proportions of $1 / 2.0$ / $<0.001$.

RCAM-hGH and its plasmin digest were compared to hGH in man on the basis of the rat "weight gain" unit. Since hGH, RCAM-hGH, and PD-RCAM-hGH have closely similar potencies in the rat weight gain assay $(6,9)$, the present findings would have been closely similar if the dosages had been calculated on the basis of weight of hormone instead of rat units of hormone.

We found that RCAM-hGH and its plasmin digest are both more potent than $\mathrm{hGH}$ in causing retention of $\mathrm{N}, \mathrm{P}$, and $\mathrm{K}$; furthermore, RCAM-hGH is less potent than hGH in causing retention of $\mathrm{Na}$ and $\mathrm{Cl}$. The enhancement in potency is greater for $\mathrm{P}$ than for $\mathrm{N}$ and $\mathrm{K}$. Consequently the profile for anabolic effect at doses $\mathrm{B}$ and $\mathrm{C}$, which is $1 / 0.06 / 4.5 / 7.5 / 5.6$ for $\mathrm{hGH}$, becomes for RCAM-hGH and PD-RCAM-hGH 1/0.14/ 5.5/2.2/2.1 and 1/0.15/5.3/2.2/2.0, respectively. In terms of the Reifenstein equations, whereas doses $\mathrm{B}$ and $\mathrm{C}$ of $\mathrm{hGH}$ cause $\Delta$ protoplasm/ $\mathrm{ECF} / \Delta$ bone of $1 / 2.0$ / $<0.001$, for RCAM-hGH and PD-RCAM-hGH these ratios are, respectively, $1 / 0.8 / 0.06$ and $1 / 0.07 / 0.05$.

We conclude that reduction and carbamidomethylation of hGH increase the hormone's capacity to stimulate formation of protoplasm and bone, and decrease the capacity to stimulate expansion of ECF. Digestion of RCAM-hGH by plasmin does not seem to cause any further alteration in this respect. The latter conclusion parallels an earlier finding (5) that the anabolic effect of the plasmin digest of $\mathrm{hGH}$ in man does not differ from that of native hGH in terms of $\Delta \mathrm{N} / \Delta \mathrm{P} / \Delta \mathrm{K} / \Delta \mathrm{Na} / \Delta \mathrm{Cl}$. The possibility that PDRCAM-hGH could differ from RCAM-hGH in the level of potencies in causing retention of elements, although not in the ratio of these potencies, is not excluded by the present study.

Conners et al. (8) compared the effect of $5 \mathrm{mg}$ daily of hGH and RCAM-hGH in reducing urinary N excretion in two GH-deficient subjects, and concluded the two preparations had similar potency in stimulating $\mathrm{N}$ retention. However, inasmuch as they did not measure fecal $\mathrm{N}$ or adjust the dose of hormone and calculated magnitude of response to body weight of the

\footnotetext{
${ }^{3} \Delta$ Protoplasm (grams) $=27 \Delta \mathrm{N}$ (grams); $\Delta \mathrm{ECF}$ (grams) $=9.6 \Delta \mathrm{Cl}$ (milliequivalents); $\Delta$ bone (grams) $=11.5(\Delta \mathrm{P}-0.068$ $\Delta \mathrm{N})$.
}

subject, or test more than one dose of hormone, it is possible that a difference in potency between the two preparations could have gone undetected in their experiments.

The mechanisms responsible for the change in anabolic profile of hGH after reduction-alkylation, demonstrated in this study, are unknown. An analogy may be found in $\mathrm{ADH}$, where replacement of L-arginine by $\mathrm{D}$-arginine in position 8 reduces pressor but not antidiuretic potency (10), and in ACTH where removal of C-terminal 14-39 abolishes corticotropic but enhances melanotropic activity (11). The profile of potencies for hGH presumably reflects the nature of hormone-receptor interaction, rate of enzymatic inactivation, and perhaps rate of enzymatic activation at each target organ (bone, muscle, kidney, etc.). A change in profile could result if these various determinants of hormonal activity are not influenced identically for all target cells by a particular chemical alteration in the structure of the hormone molecule. Altered capacity of the $\mathrm{hGH}$ derivatives to stimulate production of one or more somatomedins could also play a role.

The plasma hGH level vs. time curves in Fig. 3 suggest that the differences in anabolic potencies between hGH, RCAM-hGH, and PD-RCAM-hGH do not result from differing rates of $(a)$ absorption after intramuscular injection or $(b)$ metabolic clearance. However, a precise measurement of metabolic clearance rate by monitoring the plasma immunoreactive hGH level after intravenous injection of each hormone preparation, by the method of Taylor et al. (16), will be needed before a possible difference in rate of clearance can be excluded. In the present study,

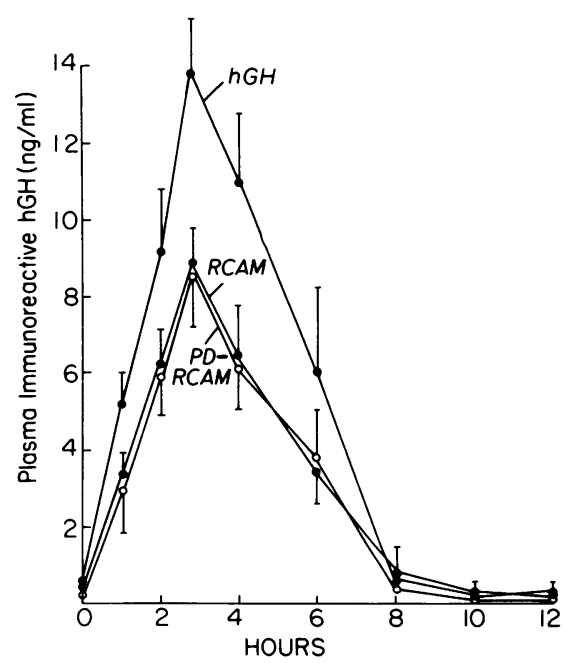

FIgURE 3 Plasma level of immunoreactive hGH in patients $1 \rightarrow 6$ before and at various times after single intramuscular injection of dose $\mathrm{C}$ of purified hGH, RCAM-hGH, or PD$\mathrm{RCAM}-\mathrm{hGH}$. Each point represents average $\pm \mathrm{SE}(n=6)$. 
because of possible idiosyncratic or allergic reaction to intravenous injection of the chemically altered forms of native hGH, this type of experiment was not done.

It is tempting to speculate that the increased retention of phosphorus seen in man with RCAM$\mathrm{hGH}$ and its plasmin digest is related to the enhanced activity of plasmin digests of native hGH (PD-hGH) when assayed in the rat by the tibia test (17-19). However, such digests do not cause increased phosphorus retention in man (5). This effect is first seen in man when native $\mathrm{hGH}$ is reduced and carbamidomethylated. Bewley et al., furthermore, did not observe increased activity of RCAM-hGH in the tibia test (6). Moreover, we have not observed increased activity of PD-hGH, RCAM-hGH, or PD-RCAM-hGH in promoting uptake of thymidine into rat costal cartilage, another process related to bone growth $(5,9)$. Thus, we are not able to relate the present observations on augmented $\mathrm{P}$ retention by RCAM-hGH and PDRCAM-hGH in man to the enhanced potency of PD$\mathrm{hGH}$ in the rat tibia assay.

Recently, fractionation of plasmin digests of RCAMhGH has resulted in the isolation of polypeptides representing residues $1-134,20-41,135-140$, and 141-191. ${ }^{4}$ These observations imply the presence of other fragments which have not yet been isolated. The relationship of these products of plasmin digestion to those reported by others has recently been summarized (20).

The present experiments suggest that chemical alteration of the disulfide bridges causes both quantitative and qualitative changes in the bioactivity of hGH for man. A whole family of such derivatives can be prepared by varying the nature of the alkylating substituent after reduction. Perhaps systematic characterization of the biologic profile of such analogues will lead eventually to a series of derivatives in which the actions of hGH on protoplasm, ECF, and bone will each be selectively enhanced or curtailed.

\section{ACKNOWLEDGMENTS}

This work was supported by U. S. Public Health Service grants RR 00039 and HD 04485 and by a grant from the Kroc Foundation.

\section{REFERENCES}

1. Bergenstal, D. M., and M. B. Lipsett. 1960. Metabolic effects of human growth hormone and growth hormone of other species in man. J. Clin. Endocrinol. 20: 14271436.

2. Henneman, D. H., and P. H. Henneman. 1960. Effects of human growth hormone on levels of blood and urinary carbohydrate and fat metabolites in man. J. Clin. Invest. 39: 1239-1245.

3. Rudman, D., S. B. Chyatte, J. H. Patterson, G. G. Gerron,

${ }^{4}$ Heymsfield et al. Unpublished data.
I. O’Beirne, J. Barlow, P. Ahmann, A. Jordan, and R. C. Mosteller. 1971. Observations on the responsiveness of human subjects to human growth hormone. J. Clin. Invest. 50: 1941-1949.

4. Reifenstein, E. C., Jr., F. Albright, and S. L. Wells. 1945. Accumulation, interpretation, and presentation of data pertaining to metabolic balances, notably those of calcium, phosphorus and nitrogen. J. Clin. Endocrinol. 5: 367-395.

5. Mills, J. B., C. R. Reagan, D. Rudman, J. L. Kostyo, P. Zachariah, and A. E. Wilhelmi. 1973. Metabolic effects of plasmin digests of human growth hormone in the rat and man. J. Clin. Invest. 52: 2941-2951.

6. Bewley, T. A., J. Brovetto-Cruz, and C. H. Li. 1969. Human pituitary growth hormone. Physicochemical investigations of the native and reduced-alkylated protein. Biochemistry. 8: 4701-4708.

7. Cerosi, E., C. H. Li, and R. Luft. 1972. Some metabolic changes induced by acute administration of native and reduced-tetra-S-carbamidomethylated human growth hormone in man. J. Clin. Endocrinol. Metab. 34: 644649.

8. Conners, M. H., S. L. Kaplan, C. H. Li, and M. M. Grumbach. 1973. Retention of biologic activity of human growth hormone in man after reduction and alkylation. J. Clin. Endocrinol. Metab. 37: 499-504.

9. Reagan, C. R., J. B. Mills, J. L. Kostyo, and A. E. Wilhelmi. 1975. Biological properties of plasmin digests of S-carbamidomethylated human growth hormone. Proc. Natl. Acad. Sci. U. S. A. 72: 1684-1686.

10. Vávra, I., A. Machová, V. Holeček, J. H. Cort, M. Zaoral, and F. Sorm. 1968. Effect of synthetic analogue of vasopressin in animals and in patients with diabetes insipidus. Lancet. I: 948-952.

11. Hofmann, K., and H. Yajima. 1962. Synthetic pituitary hormones. Recent Prog. Horm. Res. 18: 41-88.

12. Mills, J. B., R. B. Ashworth, A. E. Wilhelmi, and A. S. Hartree. 1969. Improved method for the extraction and purification of human growth hormone. J. Clin. Endocrinol. Metab. 29: 1456-1459.

13. Davis, B. J. 1964. Disc electrophoresis-II. Method and application to human serum proteins. Ann. N. Y. Acad. Sci. 121: 404-427.

14. Parlow, A. F., A. E. Wilhelmi, and L. E. Reichert, Jr. 1965. Further studies on the fractionation of human pituitary glands. Endocrinology. 77: 1126-1134.

15. Schalch, D. S., and M. L. Parker. 1964. A sensitive double antibody immunoassay for human growth hormone in plasma. Nature (Lond.). 203: 1141-1142.

16. Taylor, A. L., J. L. Finster, and D. H. Mintz. 1969. Metabolic clearance and production rates of human growth hormone. J. Clin. Invest. 48: 2349-2358.

17. Chrambach, A., R. A. Yadley, M. Ben-David, and D. Rodbard. 1973. Isohormones of human growth hormone. I. Characterization by electrophoresis and isoelectric focusing in polyacrylamide gel. Endocrinology. 93: 848857.

18. Yadley, R. A., and A. Chrambach. 1973. Isohormones of human growth hormone. II. Plasmin-catalyzed transformation and increase in prolactin biological activity. Endocrinology. 93: 858-865.

19. Singh, R. N. P., B. K. Seavey, V. P. Rice, T. T. Lindsey, and U. J. Lewis. 1974. Modified forms of human growth hormone with increased biological activities. Endocrinology. 94: 883-891.

20. Kostyo, J. L., and A. E. Wilhelmi. 1976. Conference on the Structure-Function Relationship of Pituitary Growth Hormone: A Report. Metab. Clin. Exp. 25: 105-124. 